\title{
Rhinovirus and acute bronchiolitis in young infants
}

\author{
Paulo M. C. Pitrez, ${ }^{1}$ Renato T. Stein, ${ }^{1}$ Larissa Stuermer, ${ }^{2}$ Izolete S. Macedo, ${ }^{3}$ \\ Virgínia M. Schmitt, ${ }^{4}$ Marcus H. Jones, ${ }^{1}$ Eurico Arruda $^{5}$
}

\begin{abstract}
Objective: To determine the prevalence of rhinovirus infection in hospitalized young infants with acute bronchiolitis.

Methods: Hospitalized children with acute bronchiolitis admitted to the Hospital São Lucas/PUCRS between May and September 2002 were selected prospectively. Nasopharyngeal samples were assayed for respiratory syncytial virus, parainfluenza, influenza and adenovirus by immunofluorescence. For rhinovirus test a reverse transcriptionpolymerase chain reaction for picornavirus was used, followed by hybridization with rhinovirus specific probes.

Results: Forty-five patients were selected for the study. The median age of the subjects studied was 2 months. Positive samples for respiratory viruses were found in 35/45 (77.8\%) subjects and $7 / 35(20 \%)$ patients had dual infection. Respiratory syncytial virus was detected in 33/35 (94\%) cases. Rhinovirus was detected in $6 / 35$ patients $(17 \%)$.

Conclusions: Rhinovirus was the second most common agent detected in nasal secretions from young infants hospitalized with acute bronchiolitis.
\end{abstract}

J Pediatr (Rio J). 2005;81(5):417-20: Rhinovirus, respiratory syncytial virus, acute bronchiolitis.

\section{Introduction}

Acute bronchiolitis $(A B)$, the most common viral infection of the lower airways of infants, is classically defined as the first episode of wheezing. The etiologic agents most often associated with this disease are the respiratory syncytial virus (RSV), parainfluenza, influenza and adenovirus. Respiratory syncytial virus is generally responsible for 60$80 \%$ of $A B$ cases during autumn and winter months. ${ }^{1-3}$ Over the last decade, other viruses have also been associated with this illness, including rhinovirus (RV), enterovirus, metapneumovirus and, more recently, coronavirus. ${ }^{4-8}$

1. Professor, Pontifícia Universidade Católica do Rio Grande do Sul (PUCRS), Porto Alegre, RS, Brazil.

2. Pediatrician, Hospital São Lucas, Pontifícia Universidade Católica do Rio Grande do Sul (PUCRS), Porto Alegre, RS, Brazil.

3. Biophysician, Faculdade de Medicina de Ribeirão Preto (FAMERP), Universidade de São Paulo (USP), Ribeirão Preto, SP, Brazil.

4. PhD. Professor, Pharmacy School, PUCRS, Porto Alegre, RS, Brazil.

5. PhD. Professor, FAMERP, USP, São Paulo, SP, Brazil.

Financial support: PUCRS, FAPERGS, FAPESP and CNPq

Manuscript received Jan 26 2005, accepted for publication Apr 252005.

Suggested citation: Pitrez PM, Stein RT, Stuermer L, Macedo IS, Schmitt $\mathrm{VM}$, Jones $\mathrm{MH}$, et al. Rhinovirus and acute bronchiolitis in young infants. J Pediatr (Rio J). 2005;81:417-20.
Rhinovirus is known to be the most common cause of upper airways infections in children. ${ }^{9-10}$ Furthermore, upper airway infections by this virus have been associated with episodes of asthma exacerbation in older children and adults. ${ }^{11-12}$ Nevertheless, Papadopoulos et al. ${ }^{13}$ demonstrated that RV may also cause lower airway infections. Previous studies have demonstrated an association between RV infection and wheezing in infants. $4,5,7,14,15$ Despite this, the prevalence of RV in young infants hospitalized because of $A B$ in particular has not been demonstrated.

In Brazil, epidemiological studies regarding the etiology of $A B$ have confirmed the results of studies in developed countries. 2,16 No prevalence studies of RV infection have been undertaken with infants hospitalized for $A B$ in Brazil. In a longitudinal study of children in a day care center in Salvador, Souza et al. ${ }^{10}$ demonstrated an elevated prevalence of RV infection and a frequent association with wheezing in infants from 2 to 6 months old. In addition to this, Camara et al. ${ }^{14}$ demonstrated a $20 \%$ prevalence of RV infection in children under 2 years old with wheezing seen in an emergency room in São Paulo, Brazil.

Acute bronchiolitis is a disease that causes elevated morbidity worldwide and is strongly associated with recurrent 
childhood wheezing. ${ }^{17} \mathrm{~A}$ better understanding of the association between $A B$ and recurrent wheezing in childhood is essential for the prevention and treatment of the problem. Similarly, the role played by the different respiratory viruses that are responsible for $A B$ in the development of asthma is also unclear. Some studies have found an association between infant wheezing caused by RSV and RV with the development of asthma and atopic disease. ${ }^{18,19}$ Therefore, the prevalence of RV infection in $A B$ needs to be better established in order to understand better its impact in terms of public health. A study of the mechanisms by which it possibly acts on the airways in early life may increase our knowledge about recurrent childhood wheezing.

The aim of the present study is to determine the prevalence of RV infection in young infants hospitalized for $A B$ in a university hospital in the Southern region of Brazil. As a secondary objective, the characteristics of patients with RV infection will be compared with those with RSV and the frequency of recurrent wheezing will be analyzed over a period of 12 months for the infants studied.

\section{Methods}

\section{Sample selection}

Infants younger than 6 months-old with $A B$ who were hospitalized in the Hospital São Lucas of Pontifícia Universidade Católica do Rio Grande do Sul (PUCRS), between May and September 2002, were selected. Acute bronchiolitis was defined as the first episode of wheezing, associated with signs and symptoms of acute viral infection (coryza and coughing). Children were excluded if they had a previous diagnosis of cystic fibrosis, congenital heart disease, immunodeficiencies or chronic lung disease of prematurity.

After the acute episode, patients were followed up at the Pediatric Pulmonology clinic for 12 months. Data on clinical progress was recorded during consultations. In order to increase adherence to the follow-up appointments, contact was made by telephone by a member of the team during intervals between consultations. If wheezing was still present at the first consultation, this was considered as part of the initial acute episode. The diagnosis of recurrent wheezing was defined as two or more further episodes of wheezing after the first consultation.

This study was approved by the Ethics Committee from Hospital São Lucas of PUCRS. All of the parents or guardians of the patients who participated had read and signed an informed consent form.

\section{Sample collection and processing}

Nasopharyngeal aspirate was collected with an aspiration probe number 6 , introduced into the nasopharynx and connected to a suction system and a collection bottle. All samples were collected within 48 hours of hospital admission. The probe was washed with $1.5 \mathrm{ml}$ of saline after the procedure. The material collected was then sent to the laboratory for detection of respiratory viruses.

\section{Detection of respiratory viruses}

Direct immunofluorescence (Chemicon, USA) was used to test for RSV, parainfluenza, influenza and adenovirus.

Reverse transcription polymerase chain reaction (RTPCR) was used to detect RV with primers specific to the 5'untranslated region of the picornavírus genome. The resultant amplicons were then tested for hybridization on microtitration plates according to previously described methods. ${ }^{20}$

\section{Statistical analysis}

Qualitative variables were analyzed using the chi-square test or Fisher's exact test. Quantitative variables were analyzed using the $t$ and Mann-Whitney tests. The level of significance was 0.05 .

\section{Results}

Forty-five infants hospitalized with $A B$ diagnoses were enrolled during the study period and their characteristics are presented in Table 1. The median age of patients was 2 months. The majority of patients required oxygen therapy $(71 \%)$, with a short hospital stay duration (median: 2 days).

Table 1 - Characteristics of patients studied

\begin{tabular}{lc}
\hline & $\begin{array}{c}\text { Patients } \\
(\mathbf{n}=\mathbf{4 5})\end{array}$ \\
\hline Age, months & $2(1,2-3,6) *$ \\
Sex, male (\%) & $25(56)$ \\
Race, caucasian (\%) & $29(64,4)$ \\
Family history of atopic disease (\%) & $33(73,3)$ \\
Smoking at home (\%) & $31(68,9)$ \\
Oxygen therapy required (\%) & $32(71,1)$ \\
Hospital stay, days & $2(1-4,3) *$ \\
Mechanical ventilation $(\%)$ & $5(11)$ \\
\hline
\end{tabular}

* Median (25th - 75th interquartile).

Samples were positive for respiratory viruses in 35/45 $(77.8 \%)$ cases and more than one virus was detected in $7 / 35(20 \%)$ samples. The frequencies of the respiratory viruses investigated are shown in Table 2. Respiratory syncytial virus was detected in 33/35 (94\%) cases. Rhinovirus was the second most frequent etiologic agent among the patients studied ( $6 / 35$ cases, $17 \%$ ).

The characteristics of patients with RV and RSV infections are shown in Table 3. There were no statistically significant differences between the two groups in the variables studied. Four of the infants with RV infection presented this infection associated with RSV. The age of this subset was also similar to the overall set of patients.

Thirty-three infants were followed up for 12 months. There was a $26 \%$ loss of patients from the sample studied. 
Table 2 - Frequencies of the respiratory viruses in nasopharyngeal samples of children hospitalized with acute bronchiolitis $(n=35)$

\begin{tabular}{lc}
\hline & $\begin{array}{c}\text { Detected viruses } \\
\text { in nasopharyngeal } \\
\text { samples n (\%) }\end{array}$ \\
\hline Respiratory syncytial virus & $33(94.3)$ \\
Rhinovirus & $6(17.1)$ \\
Influenza & $1(2.9)$ \\
Adenovírus & $2(5.7)$ \\
Parainfluenza & 0 \\
\hline
\end{tabular}

Table 3 - Characteristics of patients with rhinovirus and respiratory syncytial virus in children hospitalized with acute bronchiolitis

\begin{tabular}{lcc}
\hline & Rhinovirus & $\begin{array}{c}\text { Respiratory } \\
\text { syncytial virus } \\
\mathbf{n = 6}=\mathbf{6 3}\end{array}$ \\
\hline Age, months $*$ & $1.6(1.2-2.7)$ & $2.3(1-3.7)$ \\
Sex, male & 4 & 16 \\
Family history of atopic disease & 4 & 23 \\
Smoking at home & 5 & 21 \\
Oxygen therapy required & 6 & 24 \\
Mechanical ventilation & 1 & 4 \\
\hline
\end{tabular}

* Values in median (25-75\% interquartile range).

Since the data from this exercise were purely descriptive, this significant loss of patients during follow-up does not result in limitations to the study from a statistical point of view. Samples for virus testing were not collected at clinical consultations. Twenty-four of this set (73\%) exhibited recurrent wheezing and three of the patients with RV infection (two of whom also had an RSV infection) also wheezed recurrently.

\section{Discussion}

For a number of years RV infection was only recognized as a disease of the upper airways. During the last decade, $\mathrm{RV}$ has been associated with exacerbations in pediatric and adult asthma patients, and in patients with cystic fibrosis and bronchopulmonary dysplasia. ${ }^{11,21-23}$ It is essential for understanding of physiopathological mechanisms of this disease to answer the question of whether RV can cause $A B$ by establishing a lower airway infection or if it is associated with the condition by indirect mechanisms. Papadopoulos et al. ${ }^{13}$ demonstrated that RV is capable of causing lower airway infection in healthy adults and those with asthma.

Previous studies have demonstrated that RV can be found in the airways of wheezing infants, at prevalence rates between $19-29 \% .4,5,7,15$ In this study, RV was the second most common agent detected in the respiratory secretions ( $17 \%$ of cases) of infants hospitalized for $A B$, which is a frequency that is comparable with the studies mentioned. Furthermore, we have demonstrated that RV can be solely detected in infants with $A B$ in the first months of life, as can be observed by the ages of the patients studied (median: 2 months of age). Souza et al., 10 in a longitudinal study of children at a day care center in Salvador, identified $\mathrm{RV}$ in $35 \%$ of cases with lower airway symptoms and no fever, with RV being more prevalent than RSV. This results might suggest that $R V$ could be associated with clinical lower airway conditions of lesser severity during the first years of life, reinforcing the importance of studying RV infection in obstructive bronchial diseases of childhood.

The patients were selected for this study by convenience, and it is impossible to estimate the number of infants lost to the study. Nevertheless, in the opinion of the authors, the absence of this information does not alter the interpretation of the results given the study design.

The possibility that RV may not be the pathogenic agent of the $A B$ episode cannot be ruled out by this study. $A$ previous study carried out in Brazil did not find any significant association between RV infection and wheezing during the first years of life. ${ }^{14}$ The detection of molecules from the RV genome in respiratory secretions from these patients could be explained by the virus persisting in the airways, suggesting successive infections (viral shedding). ${ }^{5}$ Nevertheless, this has been considered the best method of detecting RV infection and the absence of the more common $A B$ viruses in some patients favors this interpretation.

The detection of more than one virus (co-infection) in episodes of childhood wheezing has been documented in epidemiological studies in this group of patients. ${ }^{2,5,14,16} \mathrm{An}$ association of infections by RV and RSV in infants has been demonstrated before. $4,5,7,14$ Indeed, Papadopoulos et al. 5 found an association between the presence of both agents with the severity of $A B$ episodes. In this study we identified this combination in 4/6 cases of RV infection, corroborating the findings of Papadopoulos et al. However, the restricted number of cases does not allow more detailed analyses of the association with severity of $A B$ episodes. In addition to this, the absence of significant observed differences between the characteristics of the infants with $A B$ and $R V$ and with RSV alone should be interpreted with caution because of the small number of patients studied.

The observation that a significant percentage of children with $A B$ exhibit recurrent wheezing during their first years of life has been consistently demonstrated. ${ }^{17}$ In addition to this, a relationship between atopic characteristics and the presence of RV infection in childhood wheezing and also an association between RV infection in wheezing infants and the later development of asthma have been observed. 15,19 This evidence, analyzed in conjunction with our results, emphasizes the importance of investigating the relationship between $R V$ and $A B$, recurrent wheezing and the development of asthma in future studies.

The reduced frequency in our sample of other etiologic agents such as adenovirus and parainfluenza is comparable with the reports of similar studies. ${ }^{12,16}$ The limited number 
of patients in the present study was probably the result of the rigorous criteria used to define the acute episode as the first in the child's life and of the use of a single center, but we believe that it is representative of the population of infants who visit the emergency care rooms and hospital infirmaries in the city of Porto Alegre.

As a conclusion, the results of this study indicate that RV can be detected in isolation or in association with RSV in infants hospitalized for $A B$ in the first months of life. Prospective, multicenter studies are needed to better understand the role that RV plays as a cause of $A B$ and its impact on the development of asthma or recurrent wheezing in childhood.

\section{References}

1. Dubois DB, Ray CG. Viral infections of the lower respiratory tract. In: Taussig LM, Landau LI, editors. Pediatric respiratory medicine. 1st ed. St. Louis: Mosby; 1999. p. 572-9.

2. Straliotto SM, Siqueira MM, Muller RL, Fischer GB, Cunha ML, Nestor SM. Viral etiology of acute respiratory infections among children in Porto Alegre, RS, Brazil. Rev Soc Bras Med Trop. 2002;35:283-91.

3. Nascimento JP, Siqueira MM, Sutmoller F, Krawczuk MM, de Farias $\mathrm{V}$, Ferreira $\mathrm{V}$, et al. Longitudinal study of acute respiratory diseases in Rio de Janeiro: occurrence of respiratory viruses during four consecutive years. Rev Inst Med Trop Sao Paulo. 1991;33:287-96.

4. Andreolleti L, Lesay M, Deschildre A, Lambert V, Dewilde A, Wattré $P$. Differential detection of rhinovirus and enteroviruses RNA sequences associated with classical immunofluorescence assay detection of respiratory virus antigens in nasopharyngeal swabs from infants with bronchiolitis. J Med Virol. 2000;61:341-6.

5. Papadopoulos NG, Moustaki M, Tsolia M, Bossios A, Astra E, Prezerakou $A$, et al. Association of rhinovirus infection with increased disease severity in acute bronchiolitis. Am J Respir Crit Care Med. 2002;165:1285-9.

6. Greensill J, McNamara PS, Dove W, Flanagan B, Smyth RL, Hart CA. Human metapneumovirus in severe respiratory syncytial virus bronchiolitis. Emerg Infect Dis. 2003;3:372-5.

7. Jartti $T$, Lehtinen $P$, Vuorinen $T$, Osterback $R$, van den Hoogen $B$, Osterhaus AD, et al. Respiratory picornaviruses and respiratory syncytial virus as causative agents of acute expiratory wheezing in children. Emerg Infect Dis. 2004;10:1095-101.

8. Ebihara $T$, Endo R, Ma X, Ishiguro N, Kikuta $H$. Detection of human coronavirus NL63 in young children with bronchiolitis. J Med Virol. 2005;75:463-5.

9. Watt $D$. The common cold: a review of the literature. Eur J Intern Med. 2004;15:79-88.

10. Souza LS, Ramos EA, Carvalho FM, Guedes VM, Souza LS, Rocha $\mathrm{CM}$, et al. Viral respiratory infections in young children attending day care in urban Northeast Brazil. Pediatr Pulmonol. 2003;35:184-91.
11. Nicholson KG, Kent J, Ireland DC. Respiratory viruses and exacerbation of asthma in adults. BMJ. 1993;307:982-6.

12. Rakes GP, Arruda E, Ingram JM, Hoover GE, Zambrano JC, Hayden FG, et al. Rhinovirus and respiratory syncytial virus in wheezing children requiring emergency care. IgE and eosinophil analyses. Am J Respir Crit Care Med. 1999;159:785-90.

13. Papadopoulos N, Bates PJ, Bardin PG, Papi A, Leir SH, Fraenkel $D J$, et al. Rhinovirus infect the lower airways. J Infect Dis. 2000;181:1875-84.

14. Camara AA, Silva JM, Ferriani VP, Tobias KR, Macedo IS, Padovani MA, et al. Risk factors for wheezing in a subtropical environment: role of respiratory viruses and allergen sensitization. J Allergy Clin Immunol. 2004;113:551-7.

15. Korppi M, Kotaniemi-Syrjanen A, Waris M, Vainionpaa R, Reijonen TM. Rhinovirus-associated wheezing in infancy: comparison with respiratory syncytial virus bronchiolitis. Pediatr Infect Dis J. 2004;23:995-9.

16. Sutmoller F, Ferro ZP, Asensi MD, Ferreira V, Mazzei IS, Cunha BL. Etiology of acute respiratory tract infections among children in a combined community and hospital study in Rio de Janeiro. Clin Infect Dis. 1995;20:854-60.

17. Martinez FD, Wright AL, Taussig LM, Holberg CJ, Halonen M, Morgan WJ, et al. Asthma and wheezing in the first six years of life. The Group Health Medical Associates. N Engl J Med. 1995;332:133-8.

18. Sigurs N, Bjarnason R, Fridrik S, Kjellman B. Respiratory syncytial virus bronchiolitis in infancy is an important risk factor for asthma and allergy at age 7. Am J Respir Crit Care Med. 2000;161:1501-7.

19. Kotaniemi-Syrjanen A, Vainionpaa R, Reijonen TM, Waris M, Korhonen $\mathrm{K}$, Korppi M. Rhinovirus-induced wheezing in infancythe first sign of childhood asthma? J Allergy Clin Immunol. 2003;111:66-71.

20. Arruda E, Pitkaranta A, Witek TJ Jr, Doyle CA, Hayden FG. Frequency and natural history of rhinovirus infections in adults during autumn. J Clin Microbiol. 1997;35:2864-8.

21. Johnston SL, Pattemore PK, Sanderson G, Smith S, Lampe F, Josephs $L$, et al. Community study of role of viral infections in exacerbations of asthma in 9-11 year old children. BMJ. 1995;310:1225-9.

22. Collinson J, Nicholson KG, Cancio E, Ashman J, Ireland DC, Hammersley $V$, et al. Effects of upper respiratory tract infections in patients with cystic fibrosis. Thorax. 1996;51:1115-22.

23. Chidekel AS, Rosen CL, Bazzy AR. Rhinovirus infection associated with serious lower respiratory illness in patients with bronchopulmonary dysplasia. Pediatr Infect Dis J. 1997; 16:43-7.

Correspondence:

Paulo Márcio Condessa Pitrez

Av. Ipiranga, 6690

Instituto de Pesquisas Biomédicas da PUCRS, $2^{\circ}$ andar

CEP 90610-000 - Porto Alegre, RS, Brazil

Tel./Fax: +55 513384.5104

E-mail: pmpitrez@pucrs.br 